\title{
RITOS FUNERÁRIOS E EM ANTIOQUIA: \\ a propósito do Mosaico do Banquete de Mnemosyne
} RELACÓES DE SOCIABILIDADE

Funerary rites and rapports of sociability at Antioch: some remarks on the Banquet of Mnemosyne Mosaic
Gilvan Ventura da

SILVA

Universidade Federal do Espírito Santo (UFES)

gil-ventura@uol.com.br

\section{RESUMO}

Neste artigo, temos por objetivo refletir sobre as práticas mortuárias pagãs na Antiguidade Tardia, momento em que, diante da progressiva cristianização do Império Romano, observa-se uma sensivel alteração na maneira pela qual gregos e romanos lidavam com a experiência da morte. Como estudo de caso, elegemos a cidade de Antioquia, capital da província da Síria, que, na segunda metade do século IV, foi alvo de uma intensa campanha cristianizante liderada pelas autoridades eclesiásticas. Pretendemos, assim, investigar até que ponto é possivel tratar Antioquia como uma polis cristianizada, mas sem recorrer à literatura patrística. A fim de captar a dinâmica religiosa que se estabelece no cotidiano e que tende a escapar da tutela das autoridades episcopais, julgamos por bem explorar dados provenientes da cultura material, em especial dos mosaicos, estratégia capaz de aumentar o nosso grau de compreensão acerca do modus vivendi de atores sociais que, de outra maneira, permaneceriam no anonimato ou seriam conhecidos apenas por intermédio das fontes escritas.

Palavras-chave: Antiguidade Tardia; Antioquia; Ritos Funerários; Banquete; Mosaicos.

\begin{abstract}
In this article, we aim at reflecting about the pagan mortuary practices in the Late Antiquity, when, due to the progressive Christianization of the Roman Empire, occurred a deep change in the way Greeks and Romans dealt with the experience of death. As case study, we chose the city of Antioch, capital of the Syrian province, which, in the second half of the fourth century, was the scenario of a massive Christianizing campaign led by the ecclesiastical authorities. Therefore, we intend to discuss whether Antioch actually was then a Christian polis, but without considering the Patristic literature, full of misrepresentations. In order to comprehend the religious dynamic of daily life that tended to undermine the control exerted by the clergy over the town, we decided to explore the information provided by the archaeological sources, more specifically the mosaics, a strategy capable of increasing our amount of knowledge regarding the way of life of social actors who otherwise would either remain anonymous or be known by means of the written sources only.
\end{abstract}

Keywords: Late Antiquity; Antioch; Funerary Rites; Banquet; Mosaics. 


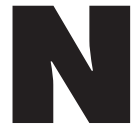

- Império Romano, entidade marcada por uma profunda diversidade étnica, religiosa e social, o cuidado devido aos mortos acompanhou amiúde as crenças e costumes locais. É bastante difícil elaborar uma síntese sobre as práticas e crenças funerárias dos antigos, a qual, ofertada como modelo interpretativo para a compreensão do sentido da morte em Roma - expressão à partida ilusória, pois, com base na realidade da Urbs conquistadora, pretende-se falar de todos os ritos fúnebres que vicejaram no extenso território imperial -, tenha condições de esgotar o assunto em poucas linhas. A despeito de tal impeditivo, que nos coloca em guarda permanente contra qualquer tentativa de generalização apressada dos acontecimentos pretéritos, não é menos verdade que, no contexto de construção da ordem imperial e de fusão crescente entre as tradições orientais dominadas (ao menos nos ambientes urbanos) pela cultura helênica e as tradições latinas, cujo epicentro seria naturalmente Roma e talvez a Península Itálica, seja possível discernir, de um lado a outro do Mediterrâneo, algumas características similares (e não raro milenares!) no que tange às concepções acerca da morte e ao tratamento dispensado aos mortos. Tais aspectos, em algumas ocasiões, se imporão de cima para baixo, como no caso dos ordenamentos imperiais, muitos deles tendo como propósito unificar os procedimentos funerários mediante determinações gerais e vinculatórias, ou seja, obrigatórias para todas as populações submetidas à lex romana, não obstante os particularismos regionais.

Dentre os costumes funerários vigentes em toda a extensão do Império, um dos mais (se não o mais) recorrente foi o de sepultar os corpos na região extra muros, ou seja, fora das muralhas que delimitavam o perímetro urbano, tido como sagrado. Isto não somente por questões de natureza religiosa, mas também de saúde pública, pois, acreditava-se, a matéria insepulta era altamente poluente, tanto em termos físicos quanto em termos sobrenaturais, razão pela qual, no século II, Adriano, retomando uma antiga determinação já contida na Lei das Doze Tábuas (século V a.C.), ${ }^{1}$ proibiu cremações ou sepultamentos num raio de pelo menos três quilômetros de distância das muralhas urbanas (RETIEF; CILLIERS, 2006, p. 129-131). No início do século seguinte, o jurisconsulto Paulo, nas suas Sententiae, ordenava que nenhum cadáver fosse sepultado em solo urbano, a fim de não macular os sacra da cidade (ARIĖS, 2014, p. 40). Em 381, Graciano, Teodósio e Valentiniano expedem um edito ordenando que "todos os corpos contidos em urnas e sarcófagos e mantidos acima do solo sejam carregados e depositados fora da cidade" (THE THEODOSIAN CODE, IX, XVII, 6). Até a época tardia, esse interdito foi observado por todos os grupos sociais, incluindo os cristãos, que, desde pelo menos o suplício de Policarpo de Esmirna, em meados do século $I I,{ }^{2}$ dispensavam uma atenção especial às relíquias dos seus defuntos ilustres, chegando mesmo a instalá-las solenemente nas basílicas e igrejas construídas intra muros, embora essa prática não tenha sido prontamente adotada em todas as regiões, pois, em 563, os bispos reunidos no Concílio de Braga ainda se opunham aos sepultamentos no recinto das igrejas (JOHNSON, 1997, p. 43).

Do ponto de vista da cultura material, a variedade de concepções e ritos em torno da morte encontrava o seu denominador comum num motivo artístico cuja presença é 
atestada em inúmeros contextos funerários até a fase tardia do Império: o Totenmahl ou "banquete dos mortos", que poderia ser representado por meio de uma escultura, pintura, mosaico ou qualquer outro suporte (JENSEN, 2008, p. 107-108). A cena clássica do Totenmahl era a do morto reclinado num divã (kliné), portando nas mãos uma taça de vinho e tendo à sua frente uma trípode sobre a qual depositavam-se as iguarias. Em algumas situações, o morto era acompanhado pela esposa (DUNBABIN, 2003, p. 129). Mais raras eram as representações de banquetes coletivos, nas quais o defunto (ou defuntos) celebrava ao lado de seus companheiros, o que emprestava à cena um caráter mais efusivo. Sem dúvida, o apego de gregos e romanos, por séculos a fio, às figurações do Totenmahl encontra-se associado menos ao desejo de neutralizar o suposto "terror da morte" por eles nutrido do que a um notável sentimento de solidariedade entre os defuntos, seus familiares e amigos. Nesse sentido, muito embora as necrópoles fossem amiúde construídas no exterior do perímetro urbano, elas nem sempre eram lugares funestos, sombrios e lúgubres, uma vez que, em diversas ocasiões, como durante as Parentalia, festival em honra aos mortos celebrado entre os dias 13 e 21 de fevereiro, banquetes costumavam acontecer junto às tumbas, quando então vivos e mortos compartilhavam alimentos e bebidas (PRIER, 1986, p. 35), realidade expressa de modo inequívoco por meio da iconografia do Totenmahl, praticamente ubíqua no Império.

Estimulados por essas considerações iniciais, nosso principal objetivo, neste artigo, é refletir sobre as práticas mortuárias pagãs na Antiguidade Tardia, momento em que, diante da progressiva cristianização do Império, observa-se pari passu uma sensivel alteração na maneira pela qual gregos e romanos lidavam com os seus mortos e com a própria experiência da morte. Como estudo de caso, elegemos a cidade de Antioquia, capital da província da Síria, que, na segunda metade do século IV, foi alvo de uma intensa campanha cristianizante por parte de líderes influentes, a exemplo dos bispos Melécio e Flaviano. A inquietação que nos move é saber até que ponto é possivel tratar Antioquia como uma polis cristianizada, mas sem recorrer à literatura patrística, deixando assim de lado o testemunho valioso, porém nem por isso menos parcial, de João Crisóstomo, pregador que por mais de uma década esteve diretamente envolvido na tarefa de dotar sua cidade natal de um ethos genuinamente cristão, em detrimento das tradições pagãs e judaicas. A fim de captar a dinâmica religiosa que se estabelece no cotidiano e que tende a escapar da tutela das autoridades episcopais, julgamos conveniente explorar os dados provenientes da cultura material, estratégia capaz de aumentar o nosso grau de compreensão acerca do modus vivendi de atores sociais que, de outra maneira, permaneceriam no anonimato ou seriam conhecidos apenas por intermédio das fontes escritas.

Tal opção, acreditamos, nos permite lançar alguma luz sobre o cotidiano da população antioquena mediante registros legados por ela mesma e, desse modo, recuperar, dentre outros elementos, crenças e práticas religiosas que desafiam a concepção segundo a qual a cidade, em fins do século IV, já fosse controlada pelos cristãos. Para tanto, partimos do pressuposto segundo o qual a interpretação, em conjunto, das fontes textuais e das 
fontes materiais - incluindo-se aí as iconográficas - deve, até onde for possível, preservar a independência de cada uma delas. Isso decerto não nos obriga a supor que os dados extraídos dos textos, monumentos, artefatos e imagens sejam mutuamente excludentes, conclusão que o trato com essas fontes em pouco tempo cuidaria de desmentir. No entanto, como nos alerta Funari (2010, p. 40-42), ao lidarmos com a cultura material em suas diferentes formas é preciso evitar a tentação de atrelar as evidências arqueológicas àquelas contidas nos textos, de tomá-las como ilustrações daquilo que já se sabia por meio da escrita, ocasião em que a cultura material se revelaria apenas um instrumento de validação das fontes textuais. Pelo contrário, uma das virtudes do trabalho com as fontes arqueológicas é a sua capacidade de iluminar aspectos insuspeitos da realidade que, não raro, contradizem as fontes textuais, numa dinâmica de confronto, ajuste e complementação de informações que, ao fim e ao cabo, habilita o historiador a compor um quadro mais denso, mais complexo e, acreditamos, mais fiel aos processos que investiga.

Estaremos dedicados aqui à análise de um dos mais peculiares mosaicos figurativos de Antioquia, o assim denominado Mosaico do Banquete de Mnemosyne, datado da segunda metade do século IV, momento em que, como dissemos, a cristianização da cidade seria para alguns fato consumado.3 Cremos que o estudo desse mosaico possa nos revelar aspectos das concepções e ritos funerários de segmentos da população que não se enquadravam na proposta cristianizante formulada pelas autoridades eclesiásticas. Por outro lado, o mosaico constitui uma fonte valiosa para o estudo das atividades cotidianas cumpridas pelas mulheres, sobre as quais, na maioria das vezes, sabemos muito mais por intermédio das vozes masculinas, o que restringe a nossa compreensão do universo feminino por ele mesmo. A exploração desse mosaico, em particular, nos permite erguer, ao menos parcialmente, o véu que encobre a maioria das mulheres romanas, em especial aquelas que, no século IV, não participam do amplo esforço de cristianização em curso, não sendo agraciadas, portanto, com laudationes, panegíricos e hagiografias destinados a perpetuar sua memória, como vemos acontecer com Melânia, Olímpia, Paula e tantas outras personagens que, alçadas a modelos de santidade, tiveram sua memória conservada e replicada. Desse modo, não devemos incorrer no equívoco de supor que as mulheres provenientes dos círculos pagãos ou judaicos, encontrando-se excluídas das correntes da literatura hagiográfica que começava então a florescer, fossem incapazes de se fazer representar por elas mesmas, de implementar por conta própria táticas visando a exprimir suas convicções religiosas e a celebrar as redes de sociabilidade das quais participavam, deixando "impresso", na pedra e em outros suportes, o registro da sua existência, conclusão que a análise do Mosaico do Banquete de Mnemosyne é capaz de refutar.

\section{Lembranças de uma existência em comum}

Em Antioquia, como de resto nas demais cidades do Império, as necrópoles situavam- se ao longo das principais rotas que partiam das muralhas em direção a outras localidades. De acordo com o plano das escavações de 1932-1939 elaborado por Doro Levi (1947), os 
arqueólogos identificaram, na cidade, seis regiões de sepultamento, três das quais concentradas nas imediações da Porta do Sul, ou seja, na saída que conduzia ao elegante subúrbio de Dafne, local de recreação bastante frequentado em virtude das suas fontes, termas e jardins (DOWNEY, 1961, p. 19).4 Esse amplo complexo funerário, instalado nas encostas mais baixas dos Montes Sílpios, abrigava igualmente sepulturas pagãs e cristãs, incluindo um martyrion coletivo sob a forma de um edifício (oikos), contendo as relíquias de muitos santos, bispos e monges, dentre os quais Inácio, o célebre bispo da cidade, morto por volta de 130, a caminho do martírio, em Roma (SOLER, 2006, p. 202).5 As necrópoles da Porta do Sul, ao que tudo leva a crer, podem ser qualificadas como loca religiosa, áreas adquiridas por famílias, associações profissionais (collegia) ou congregações religiosas (igrejas, sinagogas) para o sepultamento dos seus membros com a anuência das autoridades municipais (RETIEF; CILLIERS, 2006, p. 134). Na época da confecção do mosaico, a incineração, por séculos a principal modalidade de tratamento dos cadáveres, já havia sido suplantada pela inumação, ou seja, pelo sepultamento do corpo em hipogeus (túmulos escavados na rocha) ou em sarcófagos de terracota, pedra ou mármore, alguns ricamente decorados, e isso tanto entre os cristãos quanto entre os pagãos, como atestam as fontes arqueológicas e textuais (GABUCCl, 2005, p. 242). Cumpre observar, no entanto, que a produção de uma arquitetura funerária sob a forma de tumbas, hipogeus, pirâmides, martyria e equivalentes era apanágio de indivíduos e/ou grupos que possuíssem recursos e coesão suficientes para proporcionar um destino mais decente aos seus mortos. Pessoas de menor poder aquisitivo, como os camponeses, eram simplesmente envoltos numa mortalha e depositados numa cova, ao passo que os mendigos, desvalidos e indigentes, dos quais muito pouco sabemos, eram recolhidos e lançados, sem nenhuma cerimônia, nos loca publica, sepulturas coletivas que, uma vez repletas, eram recobertas de terra (RETIEF; CILLIERS, 2006, p. 134). Infelizmente, em virtude da suspensão definitiva, em 1939, das escavações em Antioquia e arredores, não dispomos de informações mais precisas a respeito das necrópoles urbanas da cidade.

Em 15 de abril de 1935, Jean Lassus, o representante dos Museus Nacionais de França que ocupava o posto de Diretor Assistente de Campo na temporada de escavações, ao ser notificado, por um dos moradores da região, acerca da existência de um mosaico sob sua residência, voltou-se para as tumbas situadas no assim denominado setor 24-L. O achado em questão, bastante danificado pela decomposição das tesselas, era o Mosaico do Banquete de Mnemosyne (Fig. 1), composto por um painel central representando um banquete em torno do qual dispunham-se dez figuras, conforme demonstra a reconstituição realizada pelos arqueólogos (Fig. 2). Destas figuras, restaram apenas as alegorias de Eukárpia (Fertilidade, cf. Fig. 3), Ágora (Abundância, cf. Fig. 4), do Inverno e do Solstício de Inverno (este último, em condições de conservação muito ruins). Todas as peças foram confeccionadas com tesselas de calcário, mármore e vidro segundo a técnica dos emblemata, painéis executados previamente na oficina do artesão e não in situ, ao contrário do que costumava ocorrer com a maioria dos mosaicos de pavimento (ARCHAMBEAULT, 2004, p. 
43; BUSTAMANTE, 2009, p. 90). A composição inteira media 1,77m x 2,69m, remontando à segunda metade do século IV (350-400), de acordo com a datação proposta por Doro Levi com base no estilo de decoração. Como o mosaico jazia sob uma residência ladeada por construções modernas, os arqueólogos não puderam avançar na exploração do sítio, limitando-se a constatar que a câmara fúnebre, metade da qual oculta pelas fundações de uma casa, continha, nas paredes, diversos nichos destinados a abrigar as sepulturas, além de assentos para os visitantes, como mostra a Figura 5 (MOLHOLT, 2005, p. 196; KONDOLEON, 2005, p. 121). Em época posterior, o mosaico teria sido recortado num dos lados, o que acarretou a destruição de parte do painel central, de uma seção da borda geométrica e de duas figuras laterais (ARTAL-ISBRAND, 2005, p. 95). O propósito da operação teria sido obter espaço para a instalação de um sarcófago, o que não seria de surpreender diante da alta densidade demográfica de Antioquia, uma das cidades mais populosas do Império Romano. ${ }^{6}$ Após duas semanas de trabalho, a escassez de vestígios desestimulou os arqueólogos, que, em finais de abril de 1935, decidiram suspender as escavações, motivo pelo qual os limites exatos da necrópole nunca foram fixados (MOLHOLT, 2005, p. 198). À época, diversos outros mosaicos foram recuperados, mas o único figurativo é o de Mnemosyne. $O$ mosaico, incluindo os bustos de Ágora e Eukárpia, encontram-se atualmente sob a guarda do Worcester Art Museum, em Massachusetts. Já as seções contendo os bustos do Inverno e do Solstício de Inverno foram cedidas ao Mead Art Museum, em Amherst.

Uma descrição detalhada do mosaico nos é fornecida por Rebbeca Molholt (2005), professora de História da Arte da Brown University. O painel central é composto por seis mulheres reunidas para a celebração do banquete. Em primeiro plano, temos uma mulher sentada num escabelo, em posição solene e portando nas mãos um volumen, isto é, um rolo de papiro ou pergaminho aberto. À sua esquerda veem-se, em pé, duas outras figuras femininas, trazendo provavelmente sacolas com vinho ou flores enquanto entabulam uma conversação amigável, atitude condizente com a atmosfera lúdica que o artesão desejou imprimir à cena. Reclinadas num divã circular (stibadium) vermelho e verde, há duas outras mulheres. Uma delas descansa o braço esquerdo sobre uma almofada. Com a mão direita parece acariciar a companheira que, por sua vez, repousa a mão direita sobre a fronte da mulher sentada no escabelo, numa provável demonstração de afeto. Na extrema direita, temos outra mulher carregando uma vasilha e um cântaro, objetos que seriam utilizados pelas comensais para lavar as mãos antes do início do banquete. A cena toda é marcada por uma inequívoca atmosfera de luxo. O véu (parapetasma) que recobre o fundo é adornado com faixas douradas e prateadas. As mulheres, por sua vez, ostentam túnicas (stolae) multicores, mantas (pallae) e brincos, talvez de pérolas. O uso da stola e da palla sugere tratar-se de matronas, ou seja, mulheres de boa condição social. Utensílios de mesa elegantes distribuem-se pelo aposento. Por detrás da mulher com o cântaro e a vasilha há uma ânfora de vinho sobre um suporte de metal. À sua frente, vê-se um vaso grande (kráter), artefato próprio para a mistura de vinho com água, como de hábito entre gregos e romanos. A cor amarela dos objetos nos leva a supor que fossem de bronze. Por fim, diante do divã, 
numa posição de destaque, há uma mesa contendo uma ave pronta para ser consumida. Ao redor da borda, encontram-se dispostas cinco peças de metal semelhantes a uma lua crescente. Embora não tenhamos certeza acerca do que é representado, para Christine Kondoleon (2005, p. 205) tratar-se-iam de utensílios empregados no serviço do banquete. Por fim, logo acima de uma das comensais reclinadas, lemos o vocábulo Mnemosyne (Memória) e, mais à direita, Aiókia, muito provavelmente uma corruptela de Euókia (Banquete, Festim). Segundo Dunbabin (2003, p. 185), lidas em conjunto, as inscrições exprimiriam o título da composição: Banquete da Memória. Lidas em separado, identificariam as figuras femininas situadas logo abaixo. Assim, a mulher da direita seria uma personificação do banquete dos mortos, ao passo que aquela sobre o divã seria a personificação de Mnemosyne, da memória da defunta, que se desejava perpetuar.

Como propõe Molholt (2005, p. 200 e ss.), o mosaico certamente faz alusão a uma associação profissional (collegium) de mulheres, de natureza comercial, tendo em vista que uma das alegorias femininas que integram o conjunto é a de Ágora, que tanto poderia representar a praça do mercado, na qual se negociavam os produtos, quanto a atividade comercial em si mesma, ao passo que outra alegoria, a de Eukárpia, faria alusão à fertilidade das colheitas, conectando-se assim ao culto de Deméter, a deusa da agricultura por excelência, interpretação reforçada pelas estações do ano apostas nas laterais do mosaico, símbolos dos solstícios e dos equinócios celebrados nos festivais agrícolas. Desse modo, as mulheres retratadas no mosaico estariam envolvidas no ramo de abastecimento de produtos agrícolas a Antioquia, negócio lucrativo o suficiente para lhes possibilitar não apenas a aquisição de uma câmara mortuária, mas a decoração do ambiente com um opus tessellatum policromático, artefato que, em absoluto, se encontrava ao alcance da população em geral. No Império Romano, os collegia eram associações que reuniam, sob a tutela de um patrono, membros dos estamentos médios urbanos engajados no exercício de alguma atividade profissional. O propósito dos collegia, no entanto, não se restringia ao mundo do trabalho, pois tais associações tinham igualmente por finalidade favorecer o culto à divindade padroeira do ofício, bem como prover sepultura aos seus membros, que costumavam adquirir, com recursos próprios ou dispensados pelos patronos, túmulos repartidos coletivamente (JOHNSON, 1997, p. 40). Digno de nota é o fato de que estes túmulos não eram apenas locais de sepultamento, de depósito dos corpos que, após o funeral, permaneceriam sob a guarda dos administradores do lugar, num estado de latência condizente com a noção cristã de campo santo, um espaço sagrado no qual os mortos deveriam repousar na mais completa inércia e mansidão, recebendo, quando muito, demonstrações contidas de reverência sob a forma de flores, círios e preces. Pelo contrário, um traço distintivo das necrópoles antigas era a sua condição de espaços de festa, de confraternização entre vivos e mortos, nos quais os indivíduos se reuniam de quando em quando para celebrar a memória dos entes falecidos e, ao mesmo tempo, reforçar os laços sociais, de maneira que as necrópoles constituíam um cenário privilegiado para o exercício das sociabilidades, para o intercâmbio de informação e para o reforço da coesão grupal, dando amiúde ensejo a 
comemorações ruidosas. ${ }^{7}$

\section{O convivium das mulheres}

Dentre as cerimônias associadas aos funerais, o banquete ocupava um lugar de destaque, reproduzindo-se, assim, no recinto da tumba, a mais recorrente modalidade de entretenimento no Império Romano, presente na vida dos indivíduos do berço à sepultura. $\mathrm{Na}$ realidade, os banquetes constituíam, por assim dizer, a espinha dorsal dos cultos funerários antigos, o que explica o emprego frequente do Totenmahl. Logo no primeiro dia do sepultamento, realizava-se um banquete denominado silicernium. Nove dias depois, tinha lugar a cena novendialis, que assinalava o fim do período de luto. Outro banquete poderia ocorrer no trigésimo dia do falecimento, repetindo-se todos os anos, no aniversário de morte do defunto e no festival das Parentalia (JENSEN, 2008, p. 117). Na medida em que, segundo a cosmovisão dos antigos, por muito tempo compartilhada pelos cristãos, diga-se de passagem, as sepulturas eram locais de reunião, de encontro entre mortos e vivos, era usual que os familiares e amigos do defunto as ocupassem regularmente para cear, o que deu origem a toda uma "infraestrutura" de comensalidade funerária que incluía a instalação de acomodações (biclinia, triclinia ou stibaria) para os convivas, por vezes acompanhadas da mesa (mensa) de refeições. Os túmulos mais sofisticados ou melhor geridos poderiam inclusive conservar, como parte do mobiliário, utensílios comumente utilizados no banquete (taças, potes, tigelas, ânforas e outros). Algumas necrópoles contavam até mesmo com aprovisionamento de água a fim de facilitar o serviço e o asseio dos convidados (JENSEN, 2008 , p. 120). As lápides, sarcófagos e urnas, por sua vez, costumavam conter orifícios por meio dos quais as oferendas e libações eram introduzidas, permitindo ao defunto "degustar" do mesmo repasto ofertado aos vivos (RETIEFF; CILLIERS, 2006, p. 141).

O banquete romano, denominado convivium, comportava algumas particularidades que o distinguiam do seu congênere, o symposion grego, com um impacto direto sobre o significado do evento. Na Grécia, o symposion foi, durante muito tempo, uma reunião de aristocratas do sexo masculino que, ao som de música e poesia, se dedicavam, após o jantar propriamente dito (deipnon), ao consumo de bebida alcoólica (isto é, vinho misturado com água). Desse ponto de vista, o symposion indicava, como a própria semântica do vocábulo revela, o ato de "beber junto". Em Roma, por sua vez, o banquete sugeria muito mais a experiência do "viver junto", o ato de se reunir com os amigos, não apenas para ingerir bebida, mas para socializar de modo amplo. Daí a opção dos romanos pelo vocábulo convivium em lugar de symposion, o que acentuava a importância do encontro como expressão de um estilo de vida calcado, acima de tudo, na solidariedade entre os participantes. Além disso, em comparação com a Grécia, o convivium romano era mais inclusivo, pois nele as mulheres de família (matronas) ou ao menos as da elite - e não apenas as cortesãs, flautistas e dançarinas, como no symposion - eram amiúde admitidas na condição de comensais, podendo inclusive reclinar no divã ao lado dos homens, ainda que, por certo apego ao decoro, os artistas romanos tenham por vezes optado por represen- 
tá-las sentadas, posição tida como mais apropriada para uma mulher (DUNBABIN, 2003), o que de modo algum constituía uma regra. De fato, no caso do Mosaico do Banquete de Mnemosyne, as mulheres participam nas mais distintas posições, o que, do ponto de vista do cânone artístico, atesta uma maior liberdade de representação da imagem feminina, que aparece sentada, reclinada, de pé e executando diversas funções, dentre as quais a leitura, indício suplementar de que se tratava de mulheres de certa categoria social, como a própria riqueza da indumentária comprova.

O Mosaico do Banquete de Mnemosyne nos colocaria, assim, diante de uma associação funerária gerida por mulheres que, num determinado momento, decidiram celebrar os vínculos que as uniam instalando, no chão da tumba coletiva, um mosaico policromático no qual fizeram incluir uma cena de banquete comunal, motivo que, como assinalamos, comparece com menos frequência no registro iconográfico do Totenmahl. A opção pelo banquete comunal parece traduzir não a vontade de perpetuar a memória de um defunto em particular, função que a imagem do conviva solitário cumpriria da mesma maneira, mas a de exaltar a solidariedade entre as participantes, mesma função desempenhada por alguns afrescos das catacumbas cristãs, nas quais o Totenmahl é empregado com a finalidade de realçar os laços comunitários, como vemos num exemplar proveniente da Catacumba de Calixto (Fig. 6). Desse modo, no caso do Mosaico do Banquete de Mnemosyne, o que se enfatiza é o congraçamento de um conjunto de mulheres que, reunidas num dia de festa, podem expressar o afeto que sentem umas pelas outras, como o toque singelo das mãos entre as três figuras centrais parece sugerir.

A essa altura, valeria a pena nos interrogarmos acerca da identidade das comensais: seria Mnemosyne o nome da falecida, à qual o mosaico prestaria homenagem, dúvida suscitada, mas não resolvida, por Kondoleon (2000, p. 198) e Molholt (2005, p. 200)? Ou antes, como propõe Cimok (2000, p. 30), o nome não faria alusão a nenhuma das personagens, mas antes à matriarca das Musas, personificação da memória, do ato rotineiro de lembrança, de evocação e de repetição por meio do qual as realidades pretéritas são de quando em quando atualizadas? Se considerarmos uma tendência evidente no conjunto da coleção de mosaicos de Antioquia a partir do século III - qual seja, a inclusão, nos painéis musivos, de inscrições visando a esclarecer os espectadores acerca do sentido alegórico de algumas figuras, em geral personificações de ideias, virtudes e forças da natureza, a exemplo de Tryphé (Ócio), Sotería (Salvação) e Anaenosis (Renovação) (DOWNEY, 1940), que, devido ao seu alto grau de abstração, poderiam suscitar uma leitura divergente (HUSKINSON, 2004, p. 144) -, é difícil supor que Mnemosyne identifique a falecida ou mesmo a pessoa responsável pela encomenda do mosaico. Esta conclusão é reforçada pelo vocábulo Aiochia, de inequívoco sentido alegórico, aposto ao lado de Mnemosyne. Por outro lado, ao contrário do que propõem Molholt e Kondoleon, para quem a mulher sentada seria aquela a quem se rendiam homenagens, julgamos não ser esta a interpretação correta da cena, pois, se assim o fosse, não vemos motivo para que sua identidade tivesse permanecido oculta ao passo que duas outras personagens são nomeadas por meio das inscrições. Além disso, segundo 
os cânones que regem a iconografia do Totenmahl, os defuntos, na maioria das vezes, aparecem reclinados, o que nos induziria a supor que a mulher imediatamente abaixo da inscrição fosse a defunta, e não aquela sentada no tamborete. Todas essas inconsistências na argumentação das autoras lançam sérias dúvidas sobre a identidade das figuras que compõem a cena, levando-nos a supor que Mnemosyne não tenha sido uma personagem real. Como as inscrições contidas nos mosaicos de Antioquia não fazem referência a indivíduos, razão pela qual não dispomos do nome de um único artesão ou proprietário, acreditamos que a obra exprimisse o desejo dos membros do collegium em perpetuar a lembrança, não de uma mulher em particular, mas do conjunto de mulheres que aí se reuniam de quando em quando para confraternizar, argumento muito mais razoável em se tratando da tumba de um collegium e, como tal, compartilhada por diversos membros.

\section{A agência da cultura material}

Sobre o significado da iconografia do banquete em contextos funerários, Dunbabin (2003, p. 108) destaca, acima de tudo, o caráter polissêmico do motivo: a cena poderia ser tomada como imagem dos mortos quando vivos, gozando dos prazeres da vida; como prefiguração escatológica do além-túmulo, ou seja, como antecipação de uma realidade sobrenatural e idílica, posto que festiva; ou ainda como reprodução das cerimônias fúnebres que ocorriam periodicamente nas sepulturas, sem que tenhamos condições de optar por qualquer uma dessas interpretações. Seja como for, um aspecto que nos parece altamente sugestivo no Totenmahl, expresso com clareza no Mosaico de Mnemosyne, diz respeito à capacidade da cultura material, em particular daquela que se destina ao consumo visual, de produzir uma continuidade entre o presente, o passado e o futuro, em subverter a degenerescência que atinge os corpos dos viventes, submetidos de modo inexorável à degradação após certo lapso temporal, perpetuando assim a memória dos indivíduos quando em vida, no decorrer de uma comemoração, procedimento que, inserido num contexto mágico-religioso, como o dos ritos funerários, seria capaz de despertar nos espectadores sentimentos os mais variados (conforto, alegria, saudade), como sugerem alguns autores ao se referir à agência dos monumentos e artefatos, isto é, à capacidade de interferência direta da cultura material na conduta humana (MENESES, 2012, p. 255-256). Ao mesmo tempo, por intermédio da imagem encerrada num suporte qualquer (uma fotografia, uma escultura, uma pintura), corpos que já deixaram este mundo são reintroduzidos no convívio cotidiano, superando-se a passividade aniquiladora própria dos cadáveres e reduzindo-se o gap espaço-temporal entre vivos e mortos (HALLAM; HOCKEY, 2001, p. 129).

O que o Mosaico do Banquete de Mnemosyne nos sugere, em primeiro lugar, é uma experiência de conexão sobrenatural entre os membros da associação, que se reuniriam na câmara mortuária para honrar seus mortos em torno de um opus tesselatum, um mosaico de pavimento acessivel apenas aos autorizados a ingressar no ambiente, o que confere ao artefato um caráter religioso evidente, ao contrário de outros mosaicos que, instalados nas termas ou nos aposentos das residências, não integrariam, ao menos a princípio, qualquer 
culto ou ritual. Desse modo, julgamos que o Mosaico do Banquete de Mnemosyne deva ser interpretado como elemento constitutivo dos ritos funerários realizados na tumba, de acordo com os preceitos da tradição greco-romana. Em segundo lugar, ao preservar a imagem das mulheres trajadas com os seus melhores adornos, o mosaico não apenas nos fornece um simulacro de como elas teriam sido em vida, mas antes propicia a reelaboração social das defuntas, cujo corpo emerge em sua plenitude, constituindo assim um poderoso artifício iconográfico capaz de reafirmar a continuidade da existência e de atenuar o impacto das forças dispersivas da morte sobre o tecido social, função mutatis mutandis cumprida pelo ato do banquete, motivo pelo qual, em nossa opinião, o mosaico não deve ser dissociado das cerimônias realizadas na câmara mortuária. Artefato e rito são faces de uma mesma moeda, ou seja, recursos simbólicos cuja finalidade é preservar a integridade do corpo social, mesmo quando confrontado pelo inevitável desaparecimento dos seus componentes, reduzindo assim o perigo da entropia e convertendo a dispersão em solidariedade, a ausência em presença, a morte em vida (RODRIGUES, 1983, p. 53; 1992, p. 55). Os artefatos fúnebres, incluindo os mosaicos, podem ser interpretados como peças importantes daquilo que Vovelle (1996, p. 13-14) definiu, certa vez, como a morte vivida, ou seja, um "quadro de práticas funerárias, mágicas, religiosas e cívicas que, em todos os tempos, procuraram apropriar-se da morte, atribuindo aos ritos da última passagem, dos funerais, da sepultura e do luto uma estrutura na qual se depreende ou um sistema ou [...] sistemas mesclados". Em se tratando do Mosaico do Banquete de Mnemosyne, o sistema simbólico ao qual Vovelle alude é, sem dúvida, aquele que costumamos denominar, na ausência de um termo mais apropriado, como paganismo.

Por intermédio do mosaico, podemos ter uma ideia de como, na segunda metade do século IV, a cultura greco-romana era vigorosa em Antioquia, mesmo num contexto de avanço crescente da cristianização. A tumba e o mosaico nela contido, na condição de artefatos erigidos em pedra, aspiram à duração, atuando como monumentos que, para além dos seus efeitos estéticos ou práticos imediatos, celebram determinada visão de mundo e comunicam ideias e sentimentos. Agindo nos níveis informativo e afetivo, contribuem assim para a construção da realidade social (HODDER, 1994, p. 73). A tumba não é um mero repositório de corpos ressequidos, inertes, decadentes, mas um local de ocupação regular, de encontro, de exercício da solidariedade, de festa e de reforço do carisma grupal, retroalimentando os próprios valores que orientam a vida dos usuários ou, antes, das usuárias que, a certa altura, decidiram ornar o túmulo coletivo com um opus tessellatum, mesmo adorno dos ambientes domésticos reservados aos banquetes, como os oeci e os triclinia, o que favorecia uma aproximação maior entre as comensais, tanto as do presente quanto as do passado, envolvidas, decerto, numa atmosfera solene, ritual, mas nem por isso grave, uma vez que o banquete, devido ao próprio consumo de vinho, induzia muitas vezes à liberação do comportamento e à exaltação dos sentidos (JENSEN, 2008, p. 117). 0 Mosaico do Banquete de Mnemosyne nos obriga, naturalmente, a relativizar a concepção segundo a qual, na Antiguidade, o culto aos mortos derivava, antes e acima de tudo, do 
pavor de que, sem receber os devidos cuidados, os defuntos pudessem se tornar malfazejos, causando assim danos às famílias, como propôs certa vez Ariès (ARIĖS, 2014, p. 39). Gregos e romanos, sem dúvida, acreditavam na potência mágica dos mortos (manes), em especial daqueles que morreram de morte prematura, como os supliciados e os suicidas, cujos restos mortais eram amiúde manipulados pelos feiticeiros em sortilégios agressivos (MASSONEAU, 1934). No entanto, a julgar pela recorrência do Totenhmal e pelo aparato das tumbas, os mortos eram tidos, não como vizinhos indesejáveis com os quais procuramos conservar a polidez e discorrer sobre lugares-comuns da existência (o tempo, o trânsito, o custo de vida), mas como companheiros de longa data, com os quais tinha-se o prazer de estar junto, em comemoração, o que levava os antigos a minimizar o afastamento forçado imposto pela morte mediante a ocupação rotineira das necrópoles para a confraternização.

Tal atitude com relação aos mortos será combatida com vigor pelas autoridades eclesiásticas a partir do século IV, no bojo de um movimento progressivo de esvaziamento do banquete dos mortos, cujo culto passa a ser, digamos assim, "domesticado" mediante a interferência dos bispos, para quem os defuntos deveriam ser honrados apenas com preces e oferendas eucarísticas. Ao mesmo tempo, as comemorações fúnebres são retiradas das necrópoles e transferidas para o recinto das igrejas, onde, naturalmente, poderiam ser melhor controladas pelos clérigos. Tal operação gerou, ao fim e ao cabo, um profundo deslocamento que atingiu tanto a natureza quanto a espacialidade do culto funerário (JENSEN, 2008, p. 120), ainda que seus efeitos se façam sentir de modo um tanto ou quanto desigual pela extensão do Império Romano, acompanhando as oscilações da cristianização, que pouco a pouco avança, mas de modo absolutamente errático, a despeito da miragem da Ecclesia triumphans forjada pelos autores cristãos. Quando investigamos a situação de Antioquia, uma das matrizes da própria Cristandade, deparamo-nos com uma notável atmosfera multicultural da qual o Mosaico do Banquete de Mnemosyne é um importante testemunho, o que nos conduz, por um lado, a reavaliar a clássica noção de "sobrevivência" ou "resistência" do paganismo na Antiguidade Tardia e, por outro, a redimensionar a penetração, no tecido social, das concepções e práticas cristãs. Por fim, não deixa de ser até certo ponto irônico que tal testemunho tenha como protagonistas mulheres de boa posição social, categoria que as lideranças eclesiásticas do Império tardo-antigo tentaram, por todos os meios, colocar sob o seu controle, tendo em vista o financiamento da cristianização, empresa sempre carente de patronos e de recursos materiais. 
Figura 1 - Painel central do Mosaico do Banquete de Mnemosyne

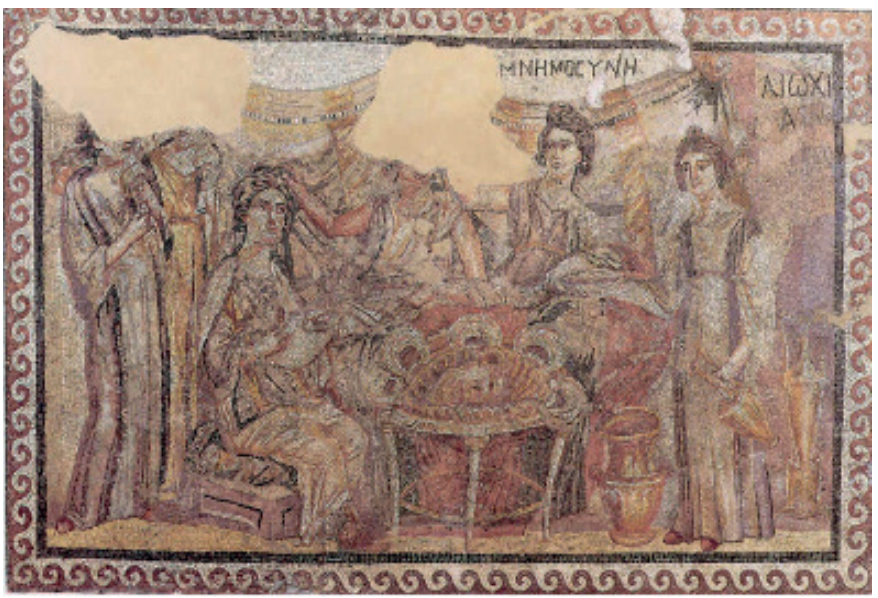

Fonte: MOLHOLT, 2005

Figura 2 - Reconstituição do painel musivo

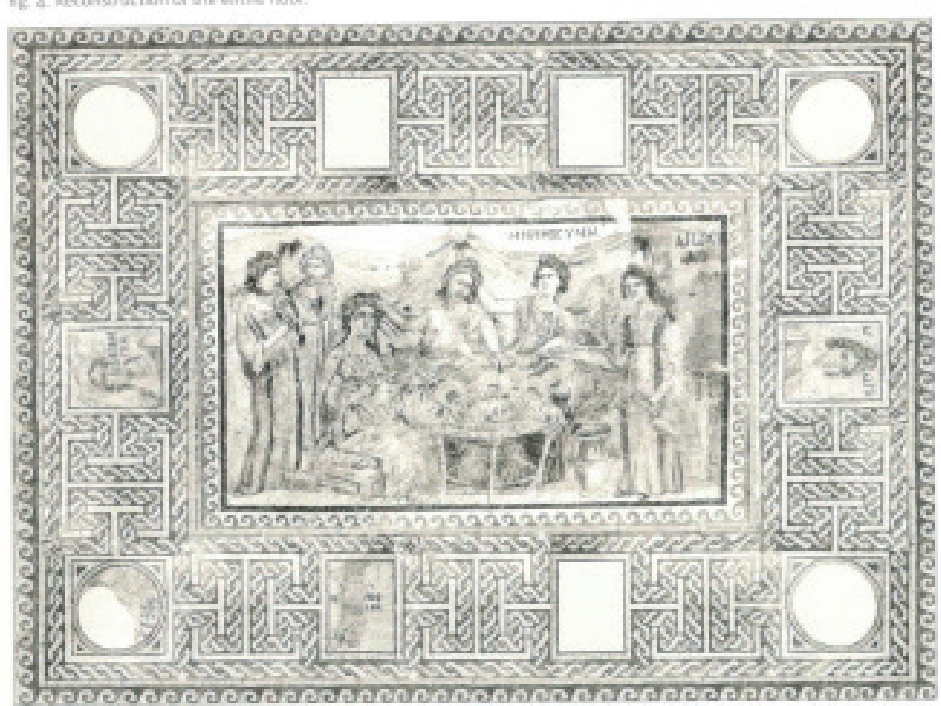


Figura 3 - Personificação de Eukárpia

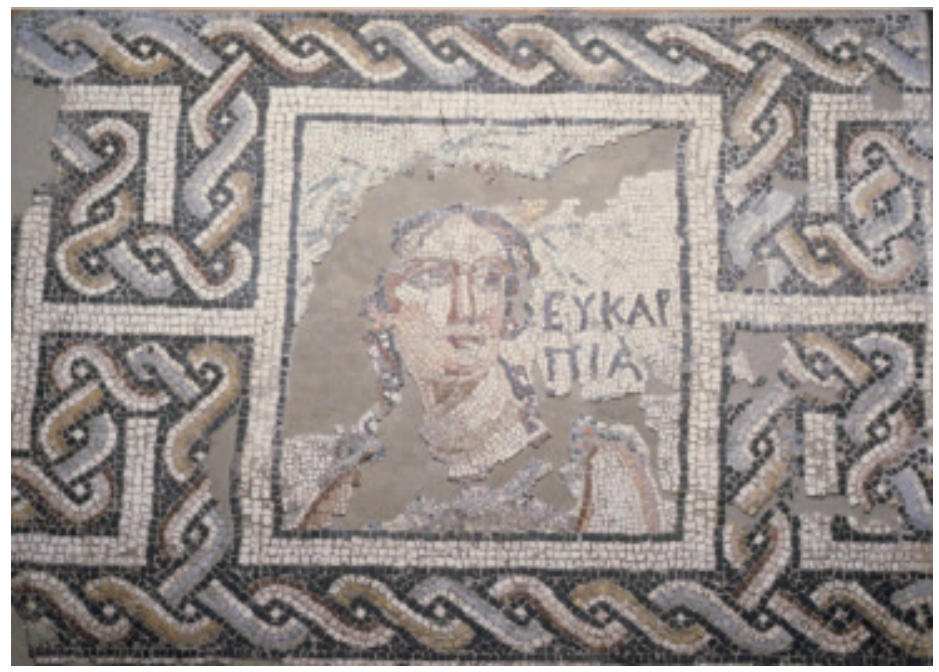

Fonte: MOLHOLT, 2005.

Figura 4 - Personificação de Ágora

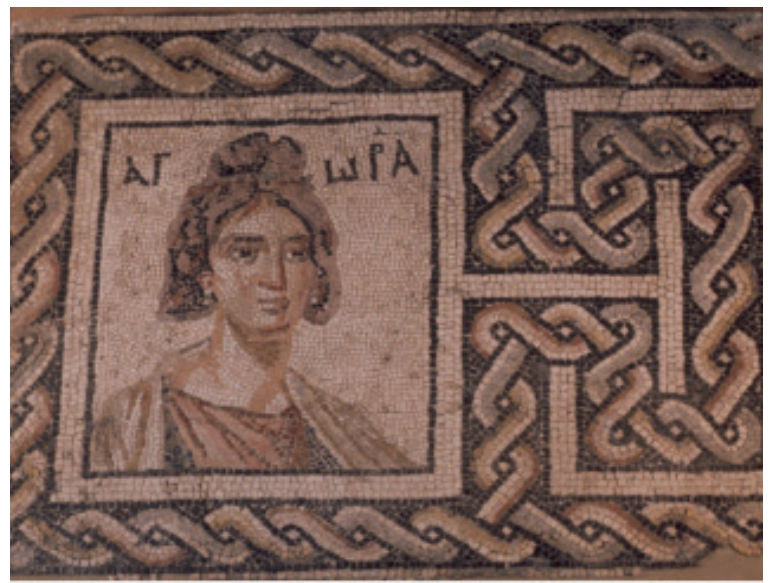

Fonte: MOLHOLT, 2005. 
Figura 5 - Câmara mortuária contendo o Mosaico do Banquete de Mnemosyne

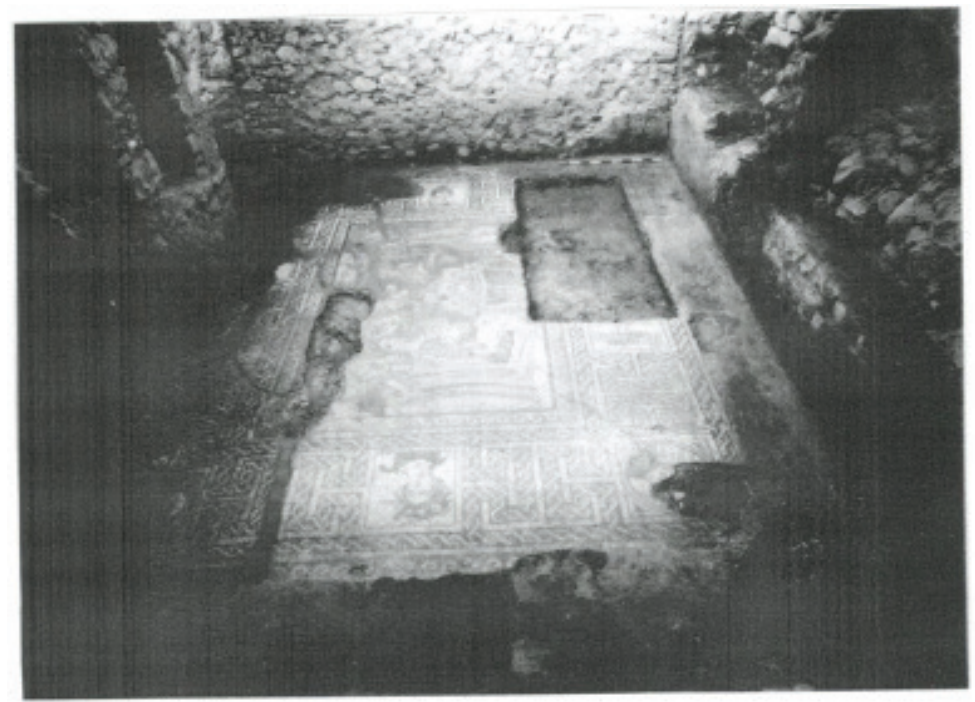

Fonte: CAMPBELL, 1988.

Figura 6 - Afresco representando o Totenmahl proveniente da Catacumba de Calixto

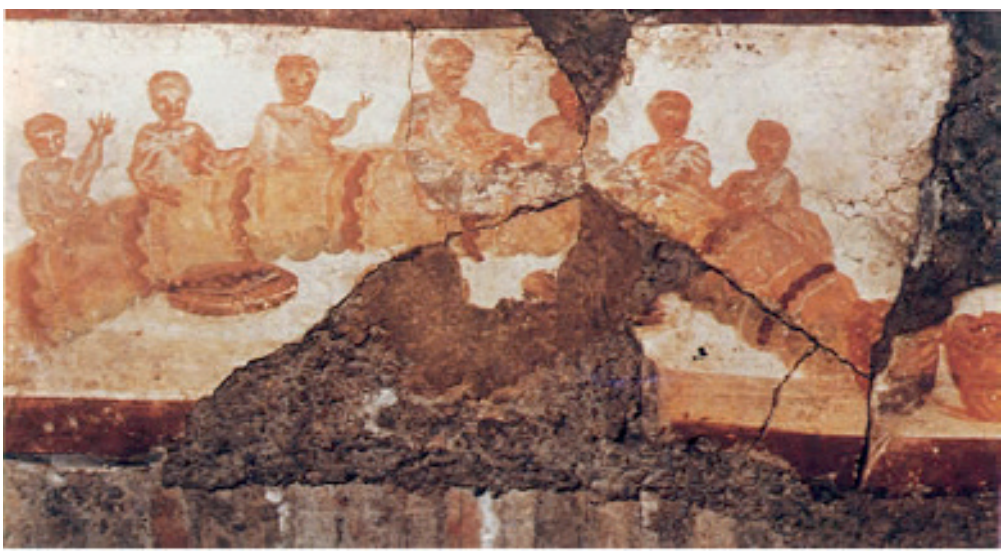

Fonte: JENSEN, 2008 


\section{Referências}

ARCHAMBEAULT, M. J. Sourcing marble used in mosaics at Antioch (Turkey). 2004. 128 f. Dissertação (Mestrado em Artes) - Programa de Pós-Graduação em Antropologia da University of Florida, Florida, 2004.

ARIÈS, P. O homem diante da morte. São Paulo: Editora da Unesp, 2014.

ARTAL-ISBRAND, P. The mosaic conservation campaign. In: BECKER, L.; KONDOLEON, C. (ed.) The arts of Antioch. Worcester: Worcester Art Museum, 2005. p. 81-113.

BERARDINO, A. Dicionário patrístico e de Antigüidades cristãs. Petrópolis: Vozes, 2002.

BUSTAMANTE, R. Mosaicos e mosaicistas no mundo romano: montando o "quebra-cabeças". In: LESSA, F. S.; SILVA, A. C. L. F. (org.). História e trabalho: entre artes e ofícios. Rio de Janeiro: Mauad X, 2009. p. 83-96.

CAMPBELL, S. The mosaics of Antioch. Toronto: Pontifical Institute of Mediaeval Studies, 1988.

CHIAVENATO, J. J. A morte, uma abordagem sociocultural. São Paulo: Moderna, 1998.

CIMOK, F. Antioch mosaics. Istanbul: A Turizm Yayinlari, 2000.

DOWNEY, G. A history of Antioch in Syria: from Seleucus to the Arab conquest. Princeton: Princeton University Press, 1961.

DOWNEY, G. Representations of abstract ideas in the Antioch mosaics. Journal of the History of Ideas, v. 1, n. 1, p. 112-113, 1940.

DOWNEY, G. The size of the population of Antioch. Transactions and Proceedings of the American Philological Association, Middletown, v. 89, p. 84-91, 1958.

DUNBABIN, K. M. D. The Roman banquet: images of conviviality. Cambridge: Cambridge University Press, 2003.

FUNARI, P. P. Arqueologia. São Paulo: Contexto, 2010.

GABUCCl, A. Dizionario delle civiltà: Roma. Milano: Mondadori, 2005.

HALLAM, E.; HOCKEY, J. Death, memory and material culture. Oxford: Berg, 2001. 
HODDER, I. Architecture and meaning: the example Neolithic houses and tombs. In: PEARSON, M. P.; RICHARDS, C. (ed.). Architecture and order. London: Routledge, 1994. p. 73-86.

HUSKINSON, J. Surveying the scene: Antioch mosaic pavements as a source for historical evidence. In: SANDWELL, I.; HUSKINSON, J. (ed.). Culture and society in Late Roman Antioch. Oxford: Oxford Bows, 2004. p. 134-152.

JENSEN, R. M. Dining with the dead: from the mensa to the altar in Christian Late Antiquity. In: BRINK, L.; GREEN, D. (ed.) Commemorating the dead: texts and artifacts in context. Studies of Roman, Jewish and Christian burials. Berlin: Walter de Gruyter, 2008. p. 107-143.

JOHNSON, M. J. Pagan-Christian burial practices of the fourth century: shared tombs? Journal of Early Christian Studies, v. 5, n. 1, p. 37-59, 1997.

KONDOLEON, C. Antioch, the lost city. Princeton: Princeton University Press, 2000.

KONDOLEON, C. What is on the banquet table? In: BECKER, L.; KONDOLEON, C. (ed.) The arts of Antioch. Worcester: Worcester Art Museum, 2005, p. 2005.

LEVI, D. Antioch mosaic pavements. Princeton: University of Princeton, 1947. v. II.

LEY DE LAS DOCE TABLAS. Edición y traducción de Antonio Ruiz Castellanos. Madrid: Ediciones Clasicas, 1991.

LIEBESCHUETZ, J. H. W. G. Antioch: city and imperial administration in the Later Roman Empire. Oxford: Oxford University Press, 1971.

MASSONEAU, E. La magie dans l'antiquité romaine. Paris: Sirey, 1934.

MENESES, U. T. B. História e imagem: iconografia/iconologia e além. In: CARDOSO, C. F. S.; VAINFAS, R. (org.) Novos domínios da História. Rio de Janeiro: Elsevier, 2012. p. 243-262.

MOLHOLT, R. Mosaic of a women's funerary banquet. In: BECKER, L.; KONDOLEON, C. (ed.) The arts of Antioch. Worcester: Worcester Art Museum, 2005. p. 196-207.

PRIER, J. La mort dans l'antiquité romaine. Rennes: Ouest France, 1986.

REBILLARD, É. Koimetérion et coemeterium: tombe, tombe sainte, nécrople. Mélanges de l'École Française de Rome, t. 105, n. 2, p. 975-1001, 1993.

RETIEF, F. P.; CILLIERS, L. Burial customs and the pollution of death in Ancient Rome: pro- 
cedures and paradoxes. Acta theologica, v. 26, n. 2, p. 128-146, 2006.

RODRIGUES, J. C. Ensaios em Antropologia do poder. Rio de Janeiro: Terra Nova, 1992.

RODRIGUES, J. C. Tabu do corpo. Rio de Janeiro: Achiamé, 1983.

SÉGUY, A. L'odeur de sainteté et la mémoire des martyrs à Antioche à la fin du IVe siècle. 2008. 121 f. Dissertação (Mestrado em Ciências da Antiguidade, menção História) - Programa de Pós-Graduação em Ciências da Antiguidade da Université de Toulouse-II-Le Mirail, Toulouse, 2008.

SILVA, G. V. Cristianismo e helenismo na Antiguidade Tardia: uma abordagem à luz dos mosaicos de Antioquia. Diálogos mediterrânicos, n. 5, p. 64-80, 2013.

SOLER, E. Le sacré et le salut à Antioche au IVe siècle apr. J.-C. Beyrouth: Institut Français du Proche-Orient, 2006.

THE THEODOSIAN CODE and Novels and Sirmondian Constitutions. Translated by c. Pharr, \& t. s. Davidson. Princeton: Princeton University Press, 1952.

VOVELLE, M. A história dos homens no espelho da morte. In: BRAET, H.; VERBEKE, W. (ed.). A morte na Idade Média. São Paulo: Editora da Universidade de São Paulo, 1996. p. 11-26.

ZETTERHOLM, M. The formation of Christianity in Antioch: a social-scientific approach to the separation between Judaism and Christianity. London: Routledge, 2003.

\section{Notas}

1 Conforme prescrevia as Leis das Doze Tábuas (X, 1), "não se enterre nem se incinere um morto dentro da cidade".

2 Segundo relato de Eusébio de Cesareia, Policarpo, bispo de Esmirna, teria morrido na fogueira em 23 de fevereiro de 167, aos 86 anos de idade. Pouco depois de sua morte, circulou, sob a forma de uma epístola endereçada à congregação de Filomélio, um opúsculo intitulado O martírio de Policarpo, o primeiro texto cristão dedicado a descrever a passio de um mártir e o primeiro a empregar o vocábulo martyr para designar um cristão executado em nome da fé, o que torna o episódio da morte de Policarpo um acontecimento decisivo para a emergência do culto aos mártires e santos (BERARDINO, 2002, p. 1176).

3 Uma breve discussão acerca dos autores que tratam da cristianização de Antioquia na segunda metade do século IV pode ser acompanhada em Silva (2013).

4 Dentre as outras três regiões identificadas como necrópoles, duas delas situavam-se na margem esquerda do Orontes, incluindo o cemitério ariano vizinho à Porta de Romanésia, no caminho que conduzia a Alexandreta e dai a Constantinopla (SÉGUY, 2008, p. 107-108). Já a terceira localizava-se no extremo norte, nas imediações do Monte Staurino.

5 Trata-se aqui, muito provavelmente, da necrópole cristã da Porta do Sul, classificada como um Koimeterion, ou seja, não um local de concentração de tumbas cristãs ordinárias, mas de martyria, de túmulos reservados aos mártires, embora haja divergências quanto a isso, pois alguns autores sugerem que a necrópole abrigava 
não apenas as relíquias dos mártires, mas também os corpos dos fiéis (SÉGUY, 2008, p. 107). Teria sido nesse koimeterion extraurbano que João Crisóstomo pronunciou, numa Sexta-Feira Santa, a homilia intitulada De coemeterio et de cruce (RÉBILLARD, 1993, p. 64).

6 Na avaliação de Downey (1958, p. 88), Antioquia contaria, no período romano, com aproximadamente 500 mil habitantes, opinião aceita por muitos especialistas, embora não haja nenhuma evidência segura que a sustente. Zetterholm (2003, p. 28) sugere uma cifra entre 300 e 400 mil, ao passo que Liebeschuetz (1971, p. 94) é menos otimista, propondo algo em torno de 150 e 300 mil. À parte essa divergência insolúvel de cálculo entre os autores, o que parece certo é que Antioquia, no século IV, experimentava uma fase de crescimento demográfico em virtude de um intenso fluxo migratório.

7 A esse respeito, vale a pena acrescentar que a noção de campo santo se impôs de modo bastante lento entre a Antiguidade e a Idade Média. Em pleno periodo medieval e a contrapelo das autoridades eclesiásticas, os cemitérios eram por vezes locais de encontro da comunidade, que aí realizava feiras e outras atividades sociais. Tanto que, em 1231, os bispos reunidos no Concilio de Rouen ameaçaram de excomunhão aqueles que dançassem nos cemitérios (CHIAVENATO, 1998, p. 50).

Gilvan Ventura da SILVA. Professor Doutor - Departamento de História da Universidade Federal do Espírito Santo (UFES) - Av. Fernando Ferrari, 514 - Goiabeiras - Vitória, ES Brasil - CEP: 29.075-910. Bolsista Produtividade 1-C do CNPq. No momento, executa o projeto de pesquisa intitulado A cidade e os usos do corpo no Império Romano: um olhar sobre a cristianização de Antioquia.

Recebido em 18/03/2016

Aprovado em 20/04/2016 